\title{
Road traffic accidents in Polonnaruwa District: Analysis of patients admitted to a surgical unit.
}

\author{
Weerawardena WAK, ${ }^{1}$ Thennegadara TGLHM, ${ }^{2}$ \\ Priyantha HGV, ${ }^{3}$ Chandrasiri PACGS, ${ }^{4}$ Disanayaka WSI ${ }^{5}$
}

\begin{abstract}
:
Introduction:

Mortality and morbidity due to Road Traffic Accidents (RTA) is a major problem in Sri Lanka. Death toll in 2017 was 3101 and there were 8144 critical accidents. Motor cycle has been the commonest vehicle type involved.
\end{abstract}

\section{Objective:}

To describe the injuries and identify causes of injury in RTAs presented to a general hospital in a semi urban region in Sri Lanka.

\section{Method:}

We prospectively analyzed all the patients admitted with a history of RTA to a surgical unit at District General Hospital Polonnaruwa, in North Central Province of Sri Lanka from 01/02/2017 for a 3 months period.

\section{Results:}

There were 199 patients in the sample with 146 (74\%) being male. 118(59\%) were drivers/riders, 70(35\%) passengers and $11(06 \%)$ pedestrians. Commonest vehicle involved was motor cycle 152(78\%).Commonest body area involved was limbs 126(67\%) followed by head 89(48\%) and face 57(31\%). 22 of 84 driver patients (30\%) did not have a valid driving license and 26(22\%) of 126 driver/pillion rider of motorcycles had not been wearing a helmet at the time. There was evidence for alcohol involvement in $37(18.6 \%)$ injured patients.

\section{Conclusion:}

The findings indicate many of the injuries due to RTAs are preventable by taking appropriate action.

Key words: Road traffic accidents, Motorcycles, Injuries; Sri Lanka, Polonnaruwa

\section{Introduction}

Road traffic accidents (RTA) are a preventable cause for injury, morbidity and mortality. ${ }^{1}$ They are the leading cause of death by injury and the tenth-leading cause of all deaths globally. An estimated 1.2 million people are killed in road crashes each year, and as many as 50 million are injured, occupying 30 percent to 70 percent of orthopedic beds in developing countries hos-

1, Consultant surgeon, District General Hospital, Matara, Sri Lanka

2, 3, 4, 5 Senior House Officer in surgery, General Hospital, Polonnaruwa, Sri Lanka

Corresponding author: Weerawardena WAK, email: kirthiweera@gmail.com> pitals. ${ }^{2}$ If present trends continue, road traffic injuries are predicted to be the third-leading contributor to the global burden of disease and injury by $2020 .^{3}$

It is estimated that approximately 2300 people died in 2005 in Sri Lanka due to road traffic crashes, approximately 300,000 were injured in non-fatal crashes and approximately 140,000 received care for their injuries at hospitals. According to statistics of Sri Lanka ministry of transport and civil aviation RTA death in 2017 is 3101, fatal accidents 2924 and critical accidents 8144 . According to Sri Lanka police, motor cycle/motored is the vehicle type involved in highest number of accidents in past years. ${ }^{4,5}$

Motorization has enhanced the lives of many individuals and societies, but the benefits have come with a price. Although the number of lives lost in road accidents in high-income countries indicates a down-

The articles in this journal are licensed under a Creative Commons Attribution 4.0 International License. 
ward trend in recent decades, for most of the world's population, the burden of road-traffic injury (economic costs) is rising. Injury and deaths due to RTA are a major public health problem in developing countries where more than $85 \%$ of all deaths and $90 \%$ of disability-adjusted life years were lost from road traffic injuries. ${ }^{6,7}$

Since road traffic injuries affect mainly males $(73 \%$ of deaths) and those between 15 and 44 years of age, this burden is creating enormous economic hardship due to the loss of family breadwinners. ${ }^{5}$

Worldwide an estimated 3247 people are killed every day and it is the second leading cause of death among people aged 5-29 years. RTA injures or disables between 20 million and 50 million people a year. RTA ranks as the 11th leading cause of death and accounts for $2.1 \%$ of all deaths globally. $90 \%$ of the RTA deaths occur in the low income and middle income countries. The most vulnerable road users are pedestrians, cyclists, two-wheeler riders, and passengers on public transport. RTA deaths are predicted to increase by $83 \%$ in developing countries and to decrease by $27 \%$ in the developed countries. It is estimated that every year RTA costs billions of rupees globally and nationally. An RTA injury puts significant strain on health care budgets. ${ }^{8}$

\section{Objective :}

To describe the injuries and identify causes of injury in RTAs in a semi urban regional area in North Central Province of Sri Lanka to plan a strategy to prevent road traffic accidents,

\section{Method:}

We prospectively analyzed all the patients admitted with a history of RTA history to a single surgical unit (surgery unit B) at District General Hospital, Polonnaruwa, in North Central Province of Sri Lanka from 01/02/2017 for 3 months. We collected data for age, sex, occupation, vehicle involved, type of accident, time of the accident, and area of the body injured with severity, cause, and involvement of alcohol, contributory factors and safety equipment use.

Ethical approval for the study was obtained from University of Rajarata.

\section{Results:}

There were 199 patients in the sample with146 males (74\%). Age range was from 18 months to 76 years (mean male 33; female 35). Of them 118(59\%) were drivers/riders. $70(35 \%)$ were passengers and $11(06 \%)$ pedestrians.

Commonest vehicle involved with accidents in this study was motor cycles 152(78\%).
Table 1: Type of vehicles involved

\begin{tabular}{|l|l|l}
\hline Vehicle type & number & $\%$ \\
\hline motor bicycles & 152 & 78 \\
\hline three wheelers & 20 & 10 \\
\hline push bicycles & 08 & 04 \\
\hline tractors & 05 & 03 \\
\hline cars & 04 & 02 \\
\hline buses & 02 & 01 \\
\hline other & 03 & 02 \\
\hline
\end{tabular}

Table 2: Possible cause for accident

\begin{tabular}{|l|l|l}
\hline Cause & Number & $\%$ \\
\hline Owner wrong driving (other than high speed) & 87 & 44 \\
\hline High speed & 28 & 14 \\
\hline wrong driving of opponent vehicle & 21 & 11 \\
\hline animals crossing road & 36 & 18 \\
\hline mechanical failure & 11 & 06 \\
\hline Poor road condition & 11 & 06 \\
\hline
\end{tabular}

Owner wrong driving has contributed to $44 \%$ of accidents in this study. Second common reason was animals crossing road in $18 \%$ of the time. Speeding was the reason in $14 \%$. Mechanical failure was responsible for $6 \%$ of accidents in this sample.( Table 2 ).

When injured body are was analysed, commonest area affected was limbs 126(67\%), followed by head $89(48 \%)$, face $57(31 \%)$, abdomen $20(11 \%)$, chest $16(09 \%)$ and neck 02(01\%) respectively. Most injuries were soft tissue injuries. 34(17\%) patients had bone fractures. 22 of 84 driver patients (30\%) did not have a valid driving license and 26(22\%) of 126 driver/pillion rider patients injured in RTAs involving motorcycles had not been wearing a helmet at the time. There was evidence for alcohol involvement in $37(18.6 \%)$ injured patients.

There were $23(12 \%)$ accidents involving overloaded vehicles. Hourly analysis of the time of RTA showed highest number of accidents occurring around $5 \mathrm{pm}$ with $41(21 \%)$ occurring around that time.

\section{Discussion}

Incidences or prevalence of road accidents are influenced by vehicular variables, volume of traffic, traffic 
flows, road geometry, road conditions, environment and other physical factors like terrain and weather patterns. Traffic volume, traffic flow and population growth have put untold pressures on drivers and other road users beyond the geometric design variables of the roads in developing countries. Incident rate of accidents as total number of accidents per kilometre road -per year are lower in developed than developing countries. ${ }^{9}$

Drivers or passengers were injured in $94 \%$ of cases our study. In a study in Eastern Sri Lanka10 the driver/passenger trauma prevalence was $87 \%$ and it was $92 \%$ in a study in Anuradhapura area. ${ }^{1}$

Use of indicators and avoiding speed and erroneous driving can prevent accidents.11In our study main cause for the accident is either wrong driving of one's own or opponent vehicle, representing 55\% (excluding high speed).

The human variables attributable to road crash consists driver's inattention or distraction, fatigue, drink-driving, poor visibility, speeding and general indiscipline, impairment of judgment of the drivers and other road users. Some research has shown that over $70 \%$ of all fatality and serious injuries is due to drivers' errors, indiscipline or judgment. The driver impairment is a significant variable of road traffic accidents both in developed and in developing countries. ${ }^{9}$ In our study wrong driving including high speed represent $69 \%$ of cases.

Speed has causal effects in road accidents and in fact it is of major concern in road safety programmes of many countries. ${ }^{9}$ High speed was responsible in $14 \%$ RTAs in this study.

Driving under the influence of alcohol is one of the main causes of RTA. Globally, some 480,000 deaths and 20 million of people get injured by drunk driving every year. In most high-income countries about $20 \%$ of fatally injured drivers have blood alcohol concentration (BAC) in excess of the legal limit. In contrast, studies in low- and middle-income countries like India have shown that between $33 \%$ and $69 \%$ of fatally injured drivers and between $8 \%$ and $29 \%$ of non fatally injured drivers had consumed alcohol before the crash. ${ }^{12}$

In this study research $18.6 \%$ of cases involved with alcohol consumption. However as this figure was obtained from patients' self report the actual rate could be higher. The proportion of patients who had consumed alcohol was $32 \%$ in the adjoining Anuradhapura district in a similar study in $2012 .{ }^{1}$

Owner wrong driving contributed to $44 \%$ of accidents in this study. Driver fatigue is a contributor to erroneous driving, often resulting from the hypnotic ef- fect especially during nighttime driving either falling asleep or exhausted tend to make serious and fatal driving errors. Statistics show that $20 \%$ of all the traffic accidents and up to one-quarter of fatal and serious accidents are due to drivers with a diminished vigilance level. Accidents related to driver's hypo-vigilance are more serious than other types of accidents, since sleepy drivers often do not take correct action prior to a collision. ${ }^{14}$

$30 \%$ drivers did not have a valid driving/ridding license. A study in Batticoloa in 2011 showed $17 \%$ of drivers/ riders were without a license. More strict legislations are needed to control driving without license..$^{10}$

Poor road design has been viewed as one of the main causes of RTA. In our this study $06 \%$ of accidents could be linked to poor roads condition. Some of the accidents are the result of improperly maintained or poorly designed roads. Narrow roads, steep curves, slope of the roads, blind corners, improper illumination, improper traffic junctions (without signals), and lack of speed signboards are found to be the major road design issues that causes accidents. At some places there are parking lots on the roadside contributing to road accidents. ${ }^{9}$

Animal crossing the road caused $18 \%$ of RTA in the study. Similar percentage was observed in a research done in Eastern Sri Lanka in 2011.10 A study in Australia showed $5.5 \%$ of all serious RTA involved with animals. ${ }^{15}$

Vehicular variables contributing to high incidences, mortality and morbidity in RTA include mechanical failure (failing to brake), flattened tyre treads, bad breaks or tyres. Anti-crash devices such as seat belts, air bags, vehicle speed, sensors monitoring the driver's performance and behaviour on the road, alcohol-vehicle locks, collapsible steering, secured car doors and wind screens which do not open upon crash will help in preventing RTA. Mechanical failure was responsible for $6 \%$ of accidents in this sample.

Commonest vehicle involved with accidents was motor cycles in this study. According to Sri Lanka police, motor cycle/motoped is the vehicle type involved in highest number of accidents in past years in Sri Lanka. A study in 2011 at Batticoloa area(Eastern Sri Lanka ) showed a similar pattern.

$22 \%$ of the riders of motor bicycle in this sample had not been wearing a helmet. In 2013, a research in North Central province of Sri Lanka showed 39\% of motor bicycle riders were not wearing a helmet at the time of RTA. ${ }^{1}$

We observed $12 \%$ vehicles with overloading as a 
cause for RTA in this sample.In a study in Bangladesh in $2009,13.9 \%$ of vehicles were overloaded when accident took place.15 Strict legislations are needed to control overloaded vehicles.

The fracture was the most common type of injury in the patients of RTA. Lower limb was the most common site of injury, followed by the head, $67 \%$ and $48 \%$ respectively. A similar trend has been demonstrated in other studies. ${ }^{16,17}$

This shows that the injury pattern is generally the same following road traffic accidents and this knowledge of injury pattern could be helpful while planning Emergency and Trauma Care Services and also in designing and implementation of safety measures. ${ }^{16,17,18,}$

The road traffic injury prevention can be achieved by avoiding over speeding, avoiding drunken driving, use of helmets by two-wheeler drivers, improving visibility, appropriate headlights and road lightings and obeying traffic rules. ${ }^{8}$ Well-maintained vehicles with good breaks, lighting, tyres etc. will reduce accidents. Older vehicles and highly polluting vehicles should be phased out. Roads should be well maintained with frequent relaying of road surfaces and markings of road safety signs. Proper footpaths for pedestrians and pedestrian crossings should be constructed at intersections. Separate lanes for slow-moving and fast-moving vehicles should be allocated. Roads and junctions should be wide and well lit so that visibility is good. ${ }^{8}$

Issuing of the driving license should be strictly based on the minimum proficiency acquired by the learners from designated driving schools. Minimum qualifications should be fixed for different categories of drivers. All drivers should be properly trained and should posses a valid driving license. Educate the drivers and traveling public about traffic rules. Rules for compulsory wearing of helmets by two wheelers must be implemented. Removal of stray animals like cattle and removal of encroachments on footpath and road margins will enable smooth flow of traffic. Preventing haphazard parking of vehicles on busy roads and intersections to ensure free flow of traffic. ${ }^{8}$ Implementation of strict legislations is needed regarding safety equipment in ridding/ driving vehicles.

\section{Conclusion:}

Commonest vehicle involved with RTA was motorcycle (78\%). Wrong driving technique was the main cause (44\%). High speed and animal crossing the road was responsible in $>30 \%$ of cases. $18.6 \%$ of injured had used alcohol and 30\% were driving without a valid driving license and many motorcyclists riding without wearing a helmet. The findings of this study clearly indicate the preventable nature and the need for strict implementation legislations. RTA preventive action is best enforced around $5 \mathrm{pm}$ to have the maximum effect.

\section{Authors declare no conflicts of interests.}

\section{References:}

1. Weerawardena WAK, Illanagasingha TDB, Piyadasa IJ, Rathnayaka SM,

Subaweera WTDUPL, Niroshana GAL. Analysis of patients admitted with history of road traffic accidents to surgical unit B Teaching Hospital Anuradhapura, Sri Lanka. Anuradhapura Medical Journal. 2013; 7(1): 2-5.

2. Mohan D. Road Safety in Less-Motorized Environments: Future Concerns, International Journal of Epidemiology. 2002; 31(3): 527-32.

3. Christopher J.L. Murray and Alan D. Lopez, eds., The Global Burden of Disease: A Comprehensive Assessment of Mortality and Disability from Diseases, Injuries, and Risk Factors in 1990 and Projected in 2020 (Boston: Harvard School of Public Health, 1996).

4. Bhalla K, Navaratne KV, Shahraz S, Bartels D, Abraham J, Dharmaratne SD Estimating the incidence of road traffic fatalities and injuries in Sri Lanka using multiple data sources. Int J Inj Contr Saf Promot. 2010 Dec;17(4):239-46.

5. Worley, H. (2006). Road traffic accidents increase dramatically worldwide. Washington, DC: Population Reference Bureau (PRB). Google Scholar

6. Ameratunga S, Hijar M, Norton R. Road-traffic injuries: Confronting disparities to address a globalhealth problem. Lancet. 2006; 367:1533-40.

7. Nantulya VM, Reich MR. The neglected epidemic: Road traffic injuries in developing countries. BMJ. 2002; 324:1139-41.

8. Gopalakrishnan S. A Public Health Perspective of Road Traffic Accidents. J Family Med Prim Care. 2012 Jul-Dec; 1(2): 144-150.

9. Mang'uriu EGN, Kenyatta J, Diang'a S. Factors that influence the incidences of road accidents in Kenya: a survey of black spots along Mombasa-Malaba road. International Academic Journal of Information Sciences and Project Management 2017; 2(1): 38-65

10.Peethambaram J, Selladurai P. Road traffic accidents in Eastern Sri Lanka: An analysis of admissions and outcome. The Sri Lanka Journal of Surgery 2011; 29(2):72-76.

11. Sharma SM, Road Traffic Accidents in India. International Journal of Advanced \& Integrated Medical Sciences, April-June 2016; 1(2):57-64 
12. Drinking and Driving: a road safety manual for decision-makers and practitioners. Geneva, Global Road Safety Partnership, 2007. Available from: http://www.who.int/roadsafety/projects/manuals/alcohol/drinking_driving.pdf .

13. Saradadevi M, Bajaj P. Driver fatigue detection using mouth and yawning analysis. Int J Comput Sci Netw Secur. 2008; 8:183-8.

14. Rowden PJ, Steinhardt, Dale A. Sheehan, MC. (2008) Road crashes involving animals in Australia. Accident Analysis and Prevention2008; 40(6): 1865-1871.

15. Jabbar MA, Islam ML, Sultana R, Akhter SFU. Risk Factors of Road Traffic Accidents (RTA) in context of Bangladesh. Journal of Dhaka Medical College .2009; 18(02):161-165.

16. Mishra B, Sinha ND, Sukhla SK, Sinha AK, "Epidemiological study of road traffic accident cases from Western Nepal," Indian Journal of Community Medicine, 2010;35(1):115-121,

17. Chalya PL, Mabula JB, Dass RM et al. "Injury characteristics and outcome of road traffic crash victims at Bugando Medical Centre in Northwestern Tanzania," Journal of Trauma Management and Outcomes, 2012;6(1): article 1.

18. Bhuyan PJ , Ahmed F. "Road traffic accident: an emerging public health problem in Assam," Indian Journal of Community Medicine. 2013;38(2):100104. 